\title{
THE HIGH INCIDENCE OF FOOT DEFORMITY IN PATIENTS WITH HIGH-LEVEL SPINA BIFIDA
}

\author{
NIGEL S. BROUGHTON, GEOFFREY GRAHAM, MALCOLM B. MENELAUS
}

From the Royal Children's Hospital, Melbourne, Australia

In a consecutive series of 124 children with spina bifida we found that $220(89 \%)$ of the 248 feet were deformed: 70 had a calcaneus deformity; 126 were in equinus; 16 were in valgus; 3 were in varus; and 5 had convex pes valgus. Operations were performed on $171(\mathbf{7 8 \%})$ of the deformed feet.

Spasticity of the muscles controlling the foot was detected in $36(51 \%)$ of the 70 calcaneus feet and in 22 (17\%) of the 126 equinus feet. The deformities were symmetrical in 94 children.

There is a high incidence of foot deformity in patients with spina bifida who have no voluntary activity in the motors of the feet.

J Bone Joint Surg [Br] 1994; 76-B:548-50.

Received 25 January 1994; Accepted 17 February 1994

It has for long been believed that foot deformity in patients with spina bifida usually results from muscle imbalance and that children without activity in the motors of the foot would therefore have no deformities (Sharrard 1967; Sharrard and Grosfield 1968). Surgeons who treat children with high-level spina bifida, however, are often faced with foot deformities in patients who have either no muscle activity in any of the motors of the foot, or spasticity in some of them. We report the incidence of foot deformities in patients with high-level spina bifida.

\section{PATIENTS AND METHODS}

Beginning in 1960, a consecutive series of 124 children (248 feet) born with thoracic, L1, L2 or L3 spina bifida was assessed yearly for the presence of foot deformity. Children who died in the first year of life were excluded from the study. All the other children were followed up

N. S. Broughton, FRCS Ed, FRCS, FRACS, Consultant Orthopaedic Surgeon

M. B. Menelaus, MD, FRCS, FRACS, Senior Orthopaedic Consultant Royal Children's Hospital, Flemington Road, Parkville, Victoria 3052, Australia.

G. Graham, FRCS, Consultant Orthopaedic Surgeon Cardiff Royal Infirmary, Newport Road, Cardiff CF2 1SZ, UK.

Correspondence should be sent to Dr N. S. Broughton.

(C)1994 British Editorial Society of Bone and Joint Surgery 0301-620X/94/4827\$2.00 from birth for a minimum of three years or until the deformity required an operation. The state of the foot immediately before surgery was recorded and subsequent changes were ignored, to exclude iatrogenic deformities. None of the children had voluntary activity in the motors of the foot, but some had spasticity.

Data were collected every six months for the first two years of life and then annually and were recorded on the Patient Data Management System (IBM PC compatible software standardised by the International Myelodysplasia Study Group). They included muscle power (graded 0 to 5), spasticity in muscles and the level of the lesion, using a modification of the method described by Sharrard (1964). This information was collected either by the surgeon treating the patient or by one of several research assistants who had been trained in Seattle and had carried out inter- and intraobserver error tests to prove the reliability of their data collection (Broughton et al 1993). One orthopaedic surgeon (MBM) had managed all but four of the patients considered in this series and his notes were available.

\section{RESULTS}

The neurosegmental lesions were at the thoracic level in 74 children, at $\mathrm{L} 1$ in 14, at $\mathrm{L} 2$ in 9 and at $\mathrm{L} 3$ in 27.

Table I. Foot deformities in 248 feet

\begin{tabular}{|c|c|c|}
\hline Deformity & Number & Percentage \\
\hline $\begin{array}{l}\text { Equinus } \\
\text { Equinovarus } \\
\text { Equinovalgus }\end{array}$ & $\begin{array}{r}70 \\
47 \\
9\end{array}$ & 51 \\
\hline $\begin{array}{l}\text { Calcaneus } \\
\text { Calcaneovarus } \\
\text { Calcaneovalgus }\end{array}$ & $\begin{array}{r}18 \\
6 \\
46\end{array}$ & 28 \\
\hline $\begin{array}{l}\text { Valgus } \\
\text { Varus } \\
\text { Convex pes valgus }\end{array}$ & $\begin{array}{r}16 \\
3 \\
5\end{array}$ & 10 \\
\hline No deformity & 28 & 11 \\
\hline
\end{tabular}

Of the 248 feet, 220 had marked deformities (Table I), the range of which was similar at all neurosegmental levels. The severity of the deformity led to surgical correction of 171 feet. Two feet were not corrected because of parental refusal, and two patients died. The rest were not operated upon as it was felt to be 
inappropriate because of the severity and the requirements of the patient.

Spasticity of the muscles affecting foot posture was present in 59 of the feet with deformity and in none of those with no deformity. Of the 70 feet with a calcaneus deformity (with or without valgus or varus), $36(51 \%)$ had spasticity, usually in the tibialis anterior, peroneus tertius or extensors of the toes. Of the 126 feet with an equinus deformity (with or without varus or valgus), 22 $(17 \%)$ had spasticity of the foot motors, usually gastrocnemius. Of the other 24 feet with deformities (valgus, varus and paralytic convex pes valgus), only $1(4 \%)$ had spasticity.

Ninety-four patients had symmetrical deformities in both limbs. Fifteen of the patients who had asymmetrical deformities had a calcaneus deformity (with or without valgus or varus) on one side and an equinus deformity (with or without valgus or varus) on the other; in only six of these was spasticity thought to account for this asymmetry. Of the five feet with paralytic convex pes valgus, two were bilateral and the other was combined with a varus foot on the other side; no spasticity was seen. The other asymmetrical deformities had a variety of combinations.

\section{DISCUSSION}

We have shown a high incidence of foot deformities in high-level spina bifida. In most patients the deformities were severe enough to require surgical correction. They were not due to voluntary motor activity since none of the patients reviewed had any such muscle activity.

Previous reports have also shown a high incidence of foot deformity in spina bifida but they have usually included all neurosegmental levels. Hayes, Gross and Dow (1964) described deformities in 161 feet in 100 children with spina bifida at all levels; only 19 of them were calcaneus deformities. Sharrard and Grosfield (1968) reported 296 feet, most of which had been operated upon, in patients with spina bifida at all segmental levels. They implied that muscle imbalance was the cause of the deformity and reported that Faradic stimulation of the motors to the foot was a good predictor of deformity. Dias (1983) described 246 feet, 220 of which had foot deformity and stated that the type of deformity was similar for all neurosegmental levels and was not dependent on voluntary motor activity.

Lindseth (1976) reported 350 children, separated according to neurosegmental level. In high-level spina bifida the incidence of club foot was 53\%; $37 \%$ of feet had no deformity, $9 \%$ had calcaneus and there were two cases of convex pes valgus.

The incidence which we report of deformity in feet with no voluntary motor activity is high. Some deformities were clearly due to spasticity and some may have been due to spasticity which we have been unable to detect. We have had no success with Faradic stimulation in the prediction of foot deformity. In view of the number of asymmetrical deformities many of which could not be explained by spasticity, it seems unlikely that habitually assumed posture is the main reason for the development of foot deformity. Intrauterine position may be the cause of some of the deformities, and some children have an appearance similar to that of arthrogryposis. Most of the equinovarus feet which were deformed at birth were rigid and difficult to treat (Fig. 1), whereas calcaneus presenting

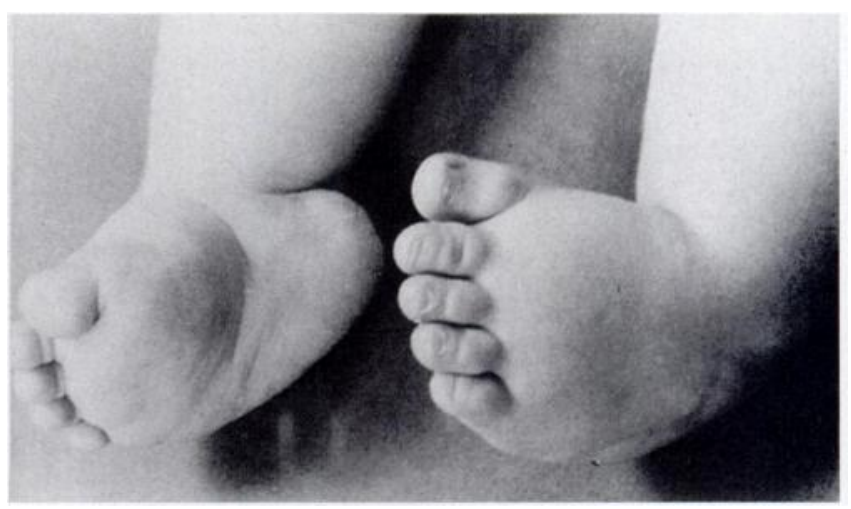

Fig. 1

Bilateral rigid equinovarus deformities in a neonate with a T12 neurosegmental lesion.

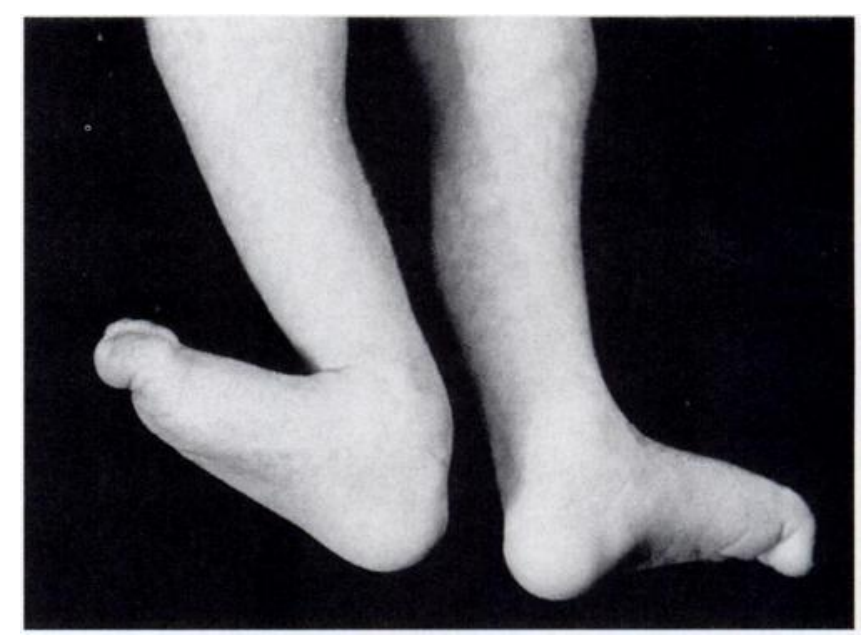

Fig. 2

Right fixed calcaneus deformity, present at birth and increasing, in a 1year-old child with no voluntary motor activity below L1, but some spasticity in tibialis anterior.

at birth is pliant (Fig. 2). Many calcaneus feet are associated with spasticity (Menelaus 1971; Bliss and Menelaus 1986).

In summary, the cause of deformity in many of our patients remains conjectural, but the concept that voluntary muscle imbalance is responsible for all foot deformities can no longer be accepted.

No benefits in any form have been received or will be received from a commercial party related directly or indirectly to the subject of this article. 


\section{REFERENCES}

Bliss DG, Menelaus MB. The results of transfer of the tibialis anterior to the heel in patients who have myelomeningocele. J Bone Joint Surg [Am] 1986; 68-A:1258-64.

Broughton NS, Menelaus MB, Cole WG, Shurtleff DB. The natural history of hip deformity in myelomeningocele. J Bone Joint Surg [Br] 1993; 75-B:760-3.

Dias LS. The foot. In: Schafer MF, Dias LS, eds. Myelomeningocele: orthopaedic treatment. Baltimore, etc: Williams \& Wilkins, 1983: 179-213.

Hayes JT, Gross HP, Dow S. Surgery for paralytic defects secondary to myelomeningocele and myelodysplasia.J Bone Joint Surg [Am] 1964; 46-A; $1577-97$.
Lindseth RE. Treatment of the lower extremity in children paralysed by myelomeningocele (birth to 18 months). Instructional Course Lectures AAOS 1976; 25:76-82.

Menelaus MB. Talectomy for equinovarus deformity in arthrogryposis and spina bifida. J Bone Joint Surg [Br] 1971; 53-B:468-73.

Sharrard WJW. Posterior iliopsoas transplantation in the treatment of paralytic dislocation of the hip. $J$ Bone Joint Surg $[B r] 1964$; 46B:426-44.

Sharrard WJW. Paralytic deformity in the lower limb. J Bone Joint Surg [Br] 1967; 49-B:731-47.

Sharrard WJW, Grosfield I. The management of deformity of the foot in myelomeningocele. J Bone Joint Surg [Br] 1968; 50-B:456-65. 